\title{
JUAN I «EL CIEGO», REY DE BOHEMIA Y CONDE DE LUXEMBURGO [¿?, 1296 - Crécy-en-Ponthieu (Francia), 1336]
}

\author{
NOGUERA PALÁU JJ ${ }^{1}$
}

Del matrimonio de Enrique VII, conocido como Enrique de Luxemburgo, Conde de Luxemburgo (1288-1313), Rey de romanos (electo en Francfort en 1308 y coronado en Aquisgrán en 1309) y Emperador del Sacro Imperio Romano Germánico (Roma, 1312), con Margarita de Brabante, hija de Juan I, duque de Brabante, nace nuestro personaje en un lugar indeterminado durante el año 1296. Fue Rey de Bohemia desde 1310 y Conde de Luxemburgo desde 1313.

El rey Juan fue perdiendo visión como consecuencia de unas cataratas, y abrumado por esta enfermedad ocular decidió consultar con los médicos más afamados de la época. El primero llegó de

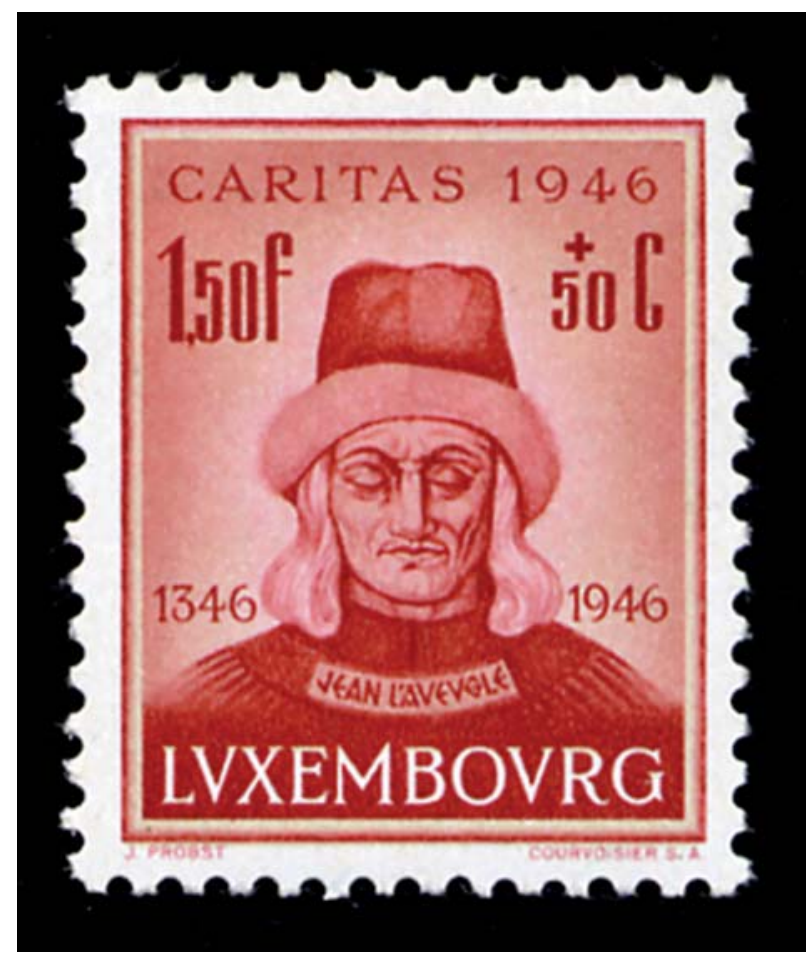

Luxemburgo: Sello 389 de Yvert 388/91 (1946).
Francia; como manifestara que no podía hacer nada para aliviar la dolencia del rey, éste ordenó que lo metieran atado en un saco y que lo echaran al río. Otro fue un médico árabe quien, conociendo el triste desenlace de su anterior colega, exigió la firma de un documento con el cual, en cualquier caso, se le permitiera regresar a su país; tampoco pudo hacer nada para mejorar la vista del rey pero, por lo menos, siguió vivo. En 1336, aprovechando un viaje a Aviñón con el rey de Francia, acudió a Montpellier para consultar con Guy de Chauliac, también conocido como Guydo de Cauliaco. Éste fue un gran cirujano, considerado el mejor de toda la Edad Media. Su obra más importante fue Chirurgicae

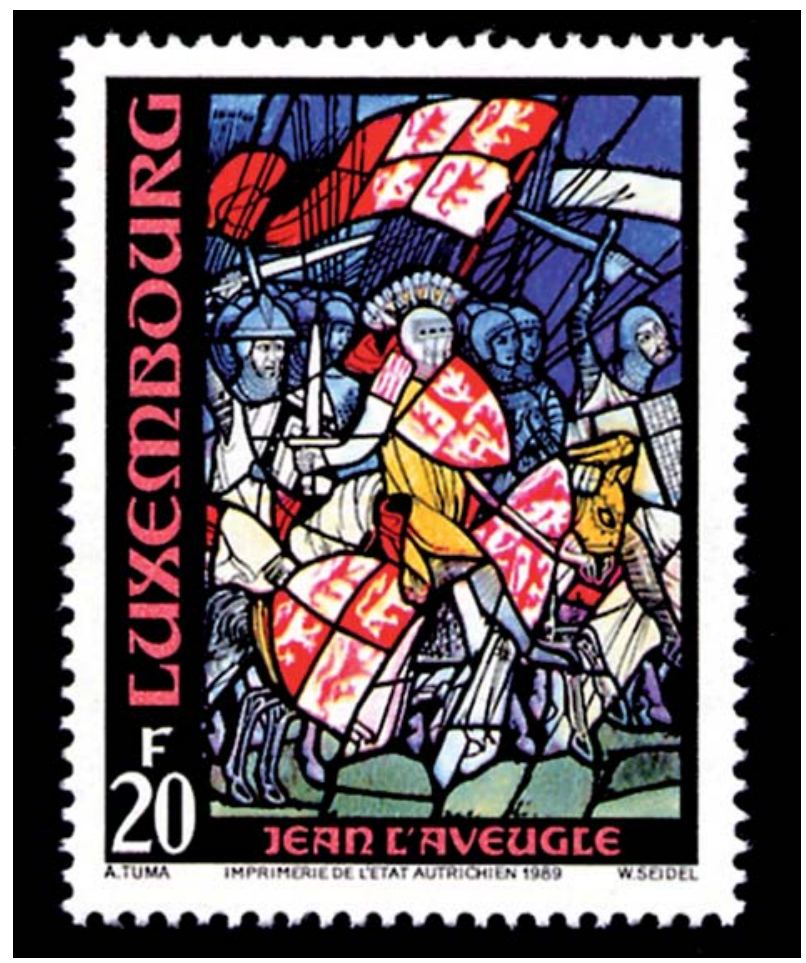

Luxemburgo: Sello 1178 de Yvert 1177/79 (1989).

\footnotetext{
${ }^{1}$ Oftalmólogo. Pamplona.

E-mail: jnoguera72b@terra.es
} 


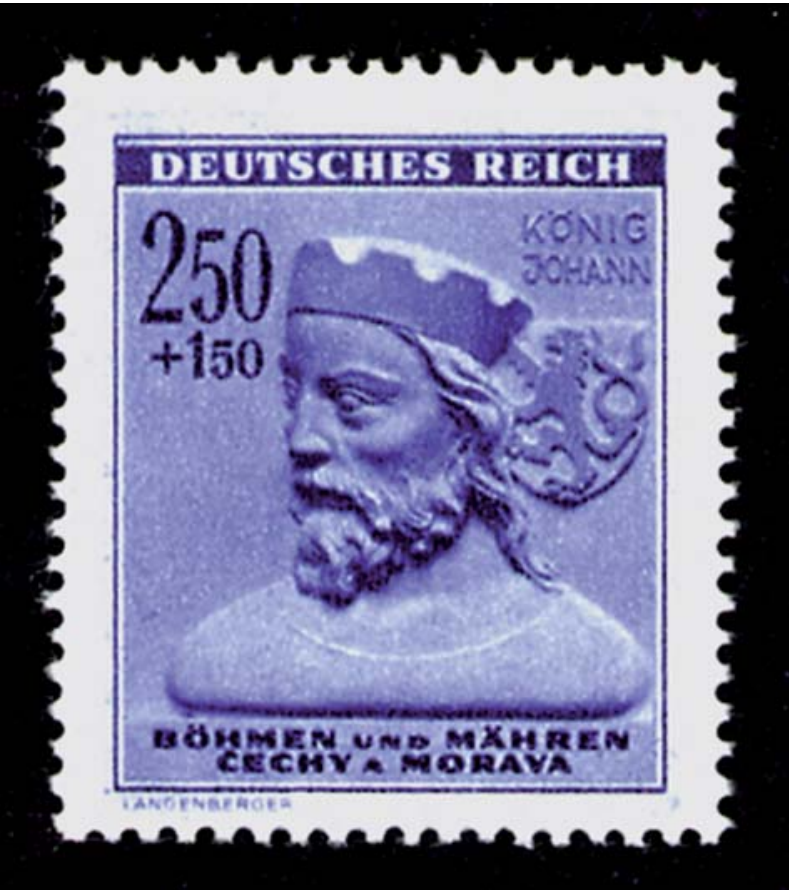

Bohemia-Moravia: Sello 104 de Yvert 102/104 (1943).

Tractatus Septem, cum Antidotario o Collectorium Artis Chirurgicalis Medicinae, más conocida como Chirurgia Magna para diferenciarla de otra obra suya, Chirurgia Parva. En su Chirurgia Magna (1363) dedicó una sección a la oftalmología y así describió la catarata:

«Se trata de una imperfección cuticular en el ojo, por delante de la pupila, que entorpece la visión. Es un extraño humor intraocular que desciende poco a poco y que se endurece por la frialdad del propio ojo. Que este humor se acumule entre la córnea y el iris (como demostró Jesús) o entre el humor acuoso y el cristalino (como defiende Galeno en su décimo libro Sobre el uso de las partes del cuerpo del hombre) no es algo que me interese ahora. El primer estadio se denomina 'Ilusión de la vista'; el segundo, 'La caída del agua' o, a veces, 'Gutta'; el tercero y último estadio, 'Catarata', porque obstaculiza la visión como la presa de un molino y como una catarata desde el cielo oculta el sol.»

Guy de Chaudiac, quizá aplicándose a sí mismo los consejos que había escrito sobre el proceder de todo cirujano (1), decidió no operar las cataratas del rey de Bohemia -las operaba por depresión-; escribió un opúsculo con una serie consejos para los pacientes con cataratas y se lo ofreció al monarca, quien no quedó satisfecho con su contenido ni con

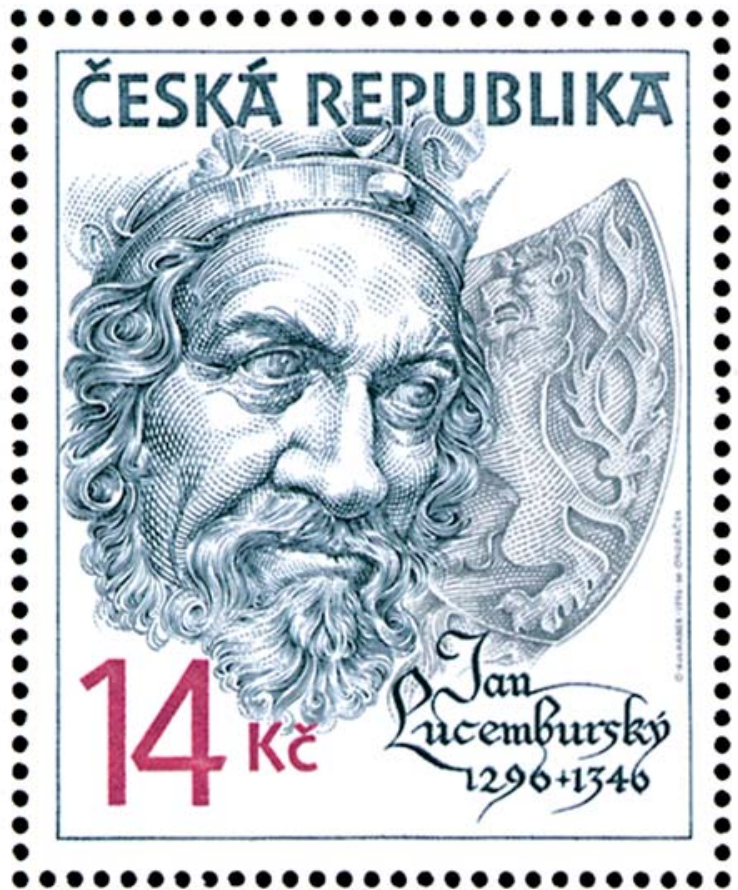

Rep. Checa: 104 de Yvert 104/07 en hojita (1996).

la atención recibida del médico francés.

Juan I de Bohemia y Conde de Luxemburgo falleció el 16 de agosto de 1346 en Crécy-en-Ponthieu (Francia), en el actual departamento de Somme, luchando como aliado del rey francés Felipe VI de Valois contra las tropas inglesas de Eduardo III, en la Guerra de los Cien Años. Para algunos, que estando ciego participara en esta batalla fue un acto heroico pero para otros muchos no fue sino una muerte deliberadamente buscada con la que dar fin a su sufrimiento por la ceguera.

Además de las emisiones correspondientes a los sellos que ilustran esta nota, hay que citar otras más de Luxemburgo, siempre con numeración del catálogo Yvert\&Tellier: 252/57 (1934), 828/31 (1974), 953/56 (1980) y 1359 (1996).

\section{NOTA}

1. Será erudito, experto, ingenioso y morigerado. Será audaz en las cosas seguras y precavido en las peligrosas. Evitará los tratamientos y prácticas defectuosos. Deberá ser amable con el enfermo, respetuoso con sus compañeros, cauteloso con sus pronósticos. Que sea modesto, digno, amable, compadecido y misericordioso; que no codicie el dinero ni sea socaliñero; que su recompensa sea según su trabajo, los medios del paciente, la clase del asunto y con su propia dignidad. 